\title{
POSITIVE ORGANIZATIONAL POTENTIAL, ORGANIZATIONAL COMMITMENT AND ORGANIZATIONAL CITIZENSHIP BEHAVIOUR: A FRENCH/POLISH COMPARISON
}

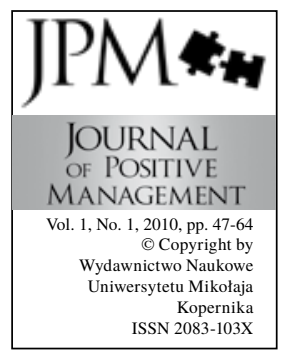

\author{
Dominique Peyrat-Guillard ${ }^{\mathrm{a}}$ \\ Aldona Glińska-Neweśb \\ aAngers University, Granem, France, \\ e-mail: dominique.peyrat@univ-angers.fr \\ ${ }^{b}$ Department of General Management, Faculty of Economic Sciences and \\ Management, Nicolaus Copernicus University, Toruń, Poland, \\ e-mail: ajka@econ.umk.pl
}

\begin{abstract}
The analyses presented in this paper are based on the first step of the research project concerning the links between Positive Organizational Potential (POP), Organizational Commitment (OC) and Organizational Citizenship Behaviour (OCB). The survey was conducted in two samples and covered French and Polish firms. The results support a model adopted in the analysis and thus the importance of influence of POP, organizational culture and climate on employees' behaviours and Organizational Development. The results also point out cultural differences between the French and Polish firms: one dimension of $\mathrm{OC}$, the willingness to continue membership in the organization and the general compliance dimension of OCB are lower in the French sample. The present paper also presents the next, planned step of the research.
\end{abstract}

Keywords: POS (Positive Organizational Scholarship), POP (Positive Organizational Potential), OC (Organizational Commitment), OCB (Organizational Citizenship Behaviour).

Paper type: Research paper

\section{Theoretical grounding}

The research project whose first results are presented in this article has been inspired by a new approach emerging in the organizational analysis. A symbolic birth of that approach was associated with the rise of the Centre for Positive Organizational Scholarship at University of Michigan and hence the new discipline name. At the beginning of 2004 the influential 'Harvard Business Review' (Fryer, 2004) described Positive Organizational Scholarship (POS) as a groundbreaking and revolutionary idea. However, despite the achievements of the research connected 
POSITIVE

ORGANIZATIONAL

Dominique Peyrat-Guillard Aldona Glińska-Neweś with University of Michigan, the new concept has its explicit roots in previous analysis and considerations conducted in the field of management.

\section{Positive Organizational Scholarship}

Positive approach in management theory concerns positive characteristics of an organization and of it's members as well as positive processes conducted in an organization. Particularly, research focuses on such phenomena as happiness, excellence and perfection, vitality, flourishing, trust, respect, empathy, etc. experienced by employees and on processes that can be qualified as generative, i.e., processes building and strengthening creative potential of employees (Cameron \& al. 2003). Stimulation of employees' creative potential, enriching their individual possibilities is crucial for any organization as it contributes to innovatory solutions and outstanding effects of the organization. But what is more, the process affects not only the organization development, but also personal goals achievement and satisfaction of employees. Among the factors influencing creative processes in organizations a key role is played by experiencing positive emotions in a workplace (such as happiness, trust, sympathy, respect). Positive emotions motivate to excellent performance, favour creative experimentation and extension of one's thinking horizons. Positive emotions are among elements of 'a positive spiral' occurring in an organization: positive emotions foster positive energy of employees, that energy is transformed into commitment affecting increase of organization's effectiveness, which in turn catalyzes further strengthening of positive emotions (Fredrickson, 2003).

The relationship between positive emotions and organizational development seems logical and sensible. Positive experiences promote general welfare of employees (physical and psychological) so they are able to cope with difficulties more easily. That is why people try to engage themselves into situations providing positive emotions and pleasant experiences. This also seems to be a theoretical proof of validity of positive approach to management. Pride and satisfaction with what is being done to stimulate sharing those good feelings with others as well as striving for new achievements. It stimulates curiosity and disposition to learn which affect in creation of new knowledge in an organization. Moreover, positive emotions are 'contagious' - they move and reflect in relations with colleagues, partners, clients (Dutton et al. 2003). This follows from the fact that those who experience positive emotions are more friendly, helpful and kind for other people. They show respect and sympathy, are more open. In turn, those who meet listed attitudes, usually reciprocate the same, in accordance with the principle of reciprocity (Cialdini, 2007). In a very natural way people desire and look for positive relations with others.

Positive attitudes and patterns of behaviour tend to persist and strengthen, as it were spontaneous, in the case of people who act this way. It happens so due to 
satisfaction and pleasure caused by effects of such practices as well as psychological mechanisms such as attribution, self-perception or cognitive dissonance. Briefly speaking, in effect of those processes individuals are establishing themselves in the belief that they behave in a certain way just because they are 'such people', that is their personality. That is a means of building personal and social identities. Although the mentioned processes relate not only to positive attitudes (such as sympathy, respect, trust, helpfulness, etc.), they seem, in particular, to reinforce and increase the likelihood of the occurrence of such feelings in the future.

The problems analyzed in the positive approach are not new and the conception is not in opposition to previous theories. A positive phenomenon, such as work satisfaction, trust, commitment, group cohesion, etc. have been analyzed and discussed so far within the field of management studies. But it is the matter of a different perspective and different accentuation. The general style of previous approaches assumed that researchers should focus on difficulties and deficits. It should be noted here that the same situation referred to psychology. Positive psychology emerged in the late 1990s as a reaction to that, became the main inspiration for Positive Organizational Scholarship.

A perspective of difficulties in both psychological and organizational analyses is not surprising as troubles and deficits are what people see and consider at first place. One can experience ten pleasant and nice situations but one unpleasant incident can destroy all positive feelings built before. That is why organizational studies have typically considered problems like resistance to change, barriers of communication, lack of commitment and motivation, etc. According to an overall assumption adopted there, if one manages to prevent a negative phenomenon, a positive one will appear automatically. But creating of positives means something more than fighting with difficulties (Caza \& al. 2007). Moreover, focusing on troubles, barriers and pathologies, paradoxically, triggers them, making appearance of positives even more difficult (Ragins et al. 2007). Foe instance, if an employee starts to analyze factors that create his/her stress at work, this can cause even greater frustration. And, even if the employee manages to eliminate stressors, this in no way means that he/she will become happier or more satisfied with his/her work. The same rule applies to groups and organizations. Concentration on negative aspects of performance creates barriers to better results and blocks their potential of development (Roberts et al. 2005). A more appropriate way is to focus on strengths not weaknesses, talents not personal deficiencies. It should be regarded as one of the main assumptions of the positive approach, however, originally it was derived from Drucker's conception of 'managing oneself' (Drucker, 2005). According to his idea, satisfaction and best results at work are most likely in the case of those who develop knowledge about themselves, particularly find their talents and capabilities. Such employees do what they can best and in a manner best suited to them. Careers built on that basis bring good results for both
POSITIVE ORGANIZATIONAL

Dominique Peyrat-Guillard Aldona Glińska-Neweś 
POSITIVE ORGANIZATIONAL

Dominique Peyrat-Guillard Aldona Glińska-Neweś

Figure 1.

Positive organizational potential as a factor of organizational development individuals (satisfaction, feeling of independence, self-development, realization of self-passions) and organization (employees have optimal contribution to the development of their company).

The positive approach enriches the previous analysis with a positive element, however, it does not deny the importance of negative features. Moreover, many authors consider negatives as essential releases of a positive phenomenon, in the sense that adaptive strengths are a product of both positive and negative feelings (Fineman, 2006). Coexistence of both stimulates development, excellent performance and organizational success.

The research project conducted by the authors of the article has been focuses on the measurement of positive features of organizations, however, in the second step of the survey it gives more consideration to 'negative' feelings, while measuring the continuance of organizational commitment.

\section{Positive Organizational Potential}

A model underlying the discussion (see Figure 1) was based on the assumption that 'positiveness' is an inner characteristic of an organization and is created primarily with the set of organizational resources. However, the positiveness of organization must be regarded as potential; it does not disclose automatically and is to stimulate in a given organization.

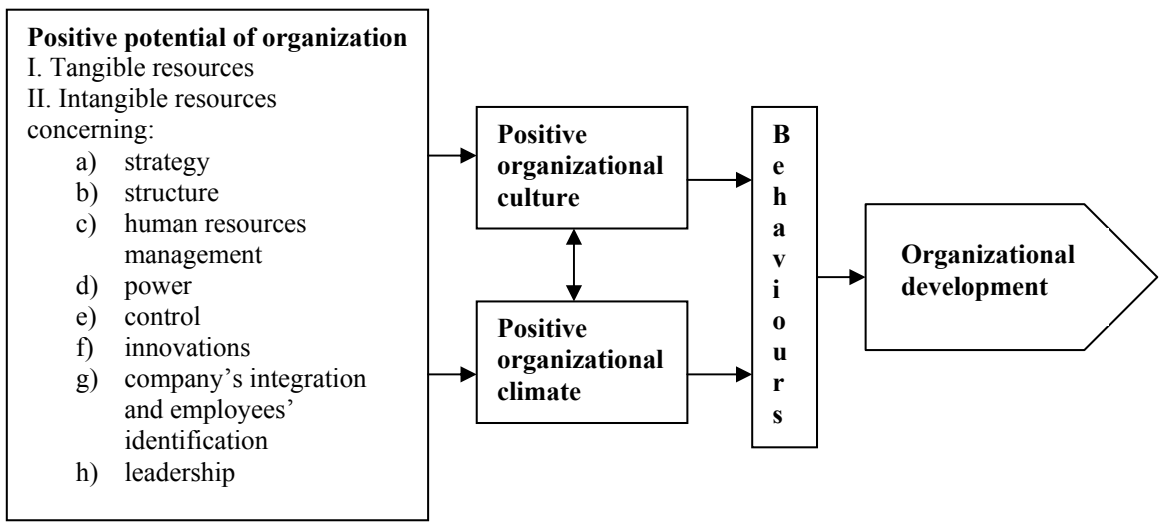

In this model the crucial role is played by employees' behaviours which are considered as the main factor of organizational development. The extent to which employees' behaviours influence organizational performance has been identified as almost 50\% (Haffer, 2010) which should be regarded as significant in comparison with the multiplicity of other factors. Employees' behaviours, in turn, are shaped by plenty of different circumstances. As the 'positive' concept of the organization 
is aimed at improving methods and techniques of management, one particular relationship is particularly interesting, i.e., the influence of organizational resources. For the purpose of this study, due to a large variety of resources' classifications, the organizational potential has been described as the set consisting of resources related to strategy, structure, human resources management, power, control, innovations, company's integration and employees' identification, and leadership. Positive organizational potential refers to such characteristics and states of organizational resources that create positive organizational culture and positive organizational climate. Those two phenomena have been intentionally extracted from the set of organizational resources due to the special role they play in a process of shaping employees' behaviour. In the model organizational culture and climate they become a kind of intermediary power between resources managed in an organization and behaviours of employees.

Within the framework of the model presented above, one type of behaviour will be studied more precisely: organizational citizenship behaviour (OCB), along with one of its antecedents: organizational commitment (OC).

\section{Organizational Citizenship Behaviour and Organizational Commitment}

In 1988 (p. 4), Organ defined OCB as 'individual behaviour that is discretionary, not directly or explicitly recognized by the formal reward system, and that in the aggregate promotes the effective functioning of the organization'. This means that OCB is discretionary in the sense of going beyond the enforceable requirement of the job description and that rewards in relation with OCBs are at best indirect and uncertain, as compared to more formal contributions (Organ, 1997). The author has also precised in this latter article that it would be preferable to avoid, if possible, reference to extra-role behaviour in defining OCB because it contains elements that many observers - and even the respondents themselves - would consider part of the job. Therefore, he has suggested defining OCB much along the lines of what Borman and Motowidlo (1993) called 'contextual performance', i.e.. 'behaviours [that] do not support the technical core itself so much as they support the broader organizational, social, and psychological environment in which the technical core must function' (p. 73). Borman and Motowidlo (1993) enumerated five categories of contextual performance, including volunteering for activities beyond a person's formal job expectations, persistence of enthusiasm and application when needed to complete important task requirements, assistance to others, following rules and prescribed procedures even when it is inconvenient, and openly espousing and defending organization objectives. Organ (1997: 90) noted that these categories 'sound much like OCB'. The difference between contextual performance and OCB is that the former concept does not require that the behaviour be extra-role nor that it be non-rewarded, it only contributes to the maintenance and/or enhancement of the context of work (Organ, 1997). 
POSITIVE

ORGANIZATIONAL

Dominique Peyrat-Guillard Aldona Glińska-Neweś

However, we have chosen the concept of OCB rather than the one of contextual performance following the point of view of Organ (1997: 91) who noted that his 'objection to contextual performance is not its definition but its name', 'cold, grey, and bloodless' and that for the moment he 'would like to hold on to OCB', even if it could be redefined as "contributions to the maintenance and enhancement of the social and psychological context that supports task performance (or the technical/ technological/production system)' (Organ, 1997: 91).

Seven different dimensions of OCB have been identified in the literature (Podsakoff and al., 2000), and these are really closed to the ones of contextual performance: (1) Altruism or Helping Behaviour, (2) Organizational Compliance, (3) Sportsmanship, (4) Organizational Loyalty, (5) Individual Initiative, (6) Civic Virtue and (7) Self Development. Helping behaviour has been identified as an important form of citizenship behaviour by virtually every researcher (Podsakoff and al., 2000). It involves voluntarily helping others with, or preventing the occurrence of, work-related problems. It includes Organ's altruism. Organizational Compliance has a long tradition of research in the OCB area (Podsakoff and al., 2000) - which has been called generalized compliance by Smith \& al. (1983). It captures a person's internalization and acceptance of the organization's rules which results in a scrupulous adherence to them, even when compliance is not monitored. Sportsmanship is a dimension that has received much less attention in the literature. It corresponds to a willingness to tolerate the inevitable inconveniences and impositions of work without complaining. Organizational Loyalty needs additional work to improve its measurement (Podsakoff and al., 2000). It entails promoting the organization to outsiders, protecting and defending it against external threats, and remaining committed to it even under adverse conditions. Individual Initiative includes behaviours that share the idea that the employee is going above and beyond the call of duty but these behaviours are difficult to distinguish empirically from in-role or task performance (Podsakoff and al., 2000). Civic Virtue is shown by a willingness to participate actively in the governance of the organization; to monitor its environment for threats and opportunities and to look out for its best interests even at great personal cost. However, this dimension was 'garbled in the process of operationalization - it came out in questionnaire rating items that referred to attending meetings, keeping up with what was going on, reading and responding to announcements and mail' (Organ, 1997: 92). Finally, Self Development includes voluntary behaviours employees engage in to improve their knowledge, skills and abilities (Podsakoff and al., 2000).

We have chosen to focus on the two most important dimensions of OCB, and the less problematic ones: altruism, which can be also designated as OCB-I (Williams \& Anderson, 1991; Organ, 1997) to indicate that it refers to contributions targeted toward an individual as they are acted out ; and generalized compliance, which 
corresponds to OCB-O (Williams \& Anderson, 1991; Organ, 1997), in the sense that it offers no immediate aid to any specific person(s), but demonstrates and sustains high standards for attendance, punctuality, conservation of organizational resources, and use of time while at work (the target is the Organization or unit as an entity). To measure OCB, we have chosen to use the instrument developed by Smith \& al. (1983) that has been the most widely used in research on this concept and that measures those two dimensions.

Many antecedents have been studied in relation to OCB. We can distinguish four categories: individual (or employee) characteristics, task characteristics, organizational characteristics, and leadership behaviour (Podsakoff and al., 2000). Among the first category, Organizational Commitment, as an employee attitude, has significant relationships with OCB. Three 'natures' or 'bases' of OC have been identified in subject literature (Meyer \& Allen, 1997): affective, continuance and normative. The first nature corresponds to an affective or emotional attachment to the organization such that a strongly committed person identifies with, is involved in, and enjoys membership in the organization. The continuance nature is viewed as a tendency to engage in consistent lines of activity based on the individual's recognition of the costs associated with discontinuing membership. The last nature view commitment as a belief about one's responsibility toward the organization and refers to an internalized moral obligation. Therefore, 'employees with strong affective commitment remain because they want to, those with strong continuance commitment because they need to, and those with strong normative commitment because they feel they ought to do so' (Allen \& Meyer, 1990: 3). It is the affective nature of organizational commitment that is correlated with OCB but it is important to take into account the other forms of commitment that can be present at the same time for the same individual. Task characteristics have also consistent relationships with OCB. The relationships between organizational characteristics and OCBs are somewhat mixed. However, the characteristics that have been studied in the literature (organizational formalization, staff support, spatial distance, etc.) could interestingly be extended to the organizational characteristics that we have taken account of in our research model. Finally, leadership behaviour is of great importance: leaders play a key role in influencing OCB.

A key point of Organ's original definition of OCB (1988) is that these behaviours enhance organizational effectiveness because they 'lubricate' the social machinery of the organization (Podsadoff and al., 1997). For many years, this assumption went untested. Now empirical evidence is available (Podsakoff and al., 2000). It provides general support for the hypothesis that OCBs are related to organizational effectiveness, although the evidence is stronger for some forms of citizenship behaviour (i.e., helping) than for others (i.e., sportsmanship and civic virtue). These authors also pointed out that 'research is also needed on 
POSITIVE

ORGANIZATIONAL

Dominique Peyrat-Guillard Aldona Glińska-Neweś the potential impact that cultural context might have on citizenship behaviour' (Podsakoff \& al., 2000: 556). Several distinct cultural effects are possible. Cultural context may affect the following: the forms of citizenship behaviour observed in organizations; the frequency of different types of citizenship behaviour; the strengths of the relationships between citizenship behaviour and its antecedents and consequences and the mechanisms through which citizenship behaviour is generated, or through which it influences organizational success. Our objective is to contribute to the study of these cultural effects by comparing the French and Polish contexts.

\section{Method}

First step

An on-line questionnaire has been elaborated by the Faculty of Economic Sciences and Management of the Nicolaus Copernicus University of Torun (Poland), within the framework of a larger research project. This questionnaire was intended to measure the positive organizational potential as a key factor of company's development. It was organized in eight major points:

I. Development supporting employee behaviours;

II. Positive culture in the organization;

III. Positive atmosphere in the organization (climate);

IV. Positive potential of the organization;

V. Development of the company;

VI. Company's performance;

VII. External factors;

VIII. Company profile.

This questionnaire has been translated into French by the Nicolaus Copernicus University (Poland) and the translation has then been checked and improved by the University of Angers (France). A letter with the comments on the project, with the direct link to the questionnaire, was sent in the year 2009 and the beginning of year 2010 to General Managers and HR Managers of firms in the two countries ${ }^{1}$. In Poland, 104 responses were collected, in France - 23.

\section{Next step}

The next step of this research will consist in comparing the employee attitudes of two French and Polish firms that we have selected on the basis of their characteristics, to conduct a fine-grained analysis. Two questionnaires will be submitted to employees: one measuring affective, normative and continuance commitment (Meyer \& Allen, 1997) and the other one measuring Organizational

${ }^{1}$ Other countries were also covered by this project but we will present here only the results concerning Poland and France. 
Citizenship Behaviour (Smith, Organ \& Near, 1983). They are presented in appendices 1 and 2 . In order to assure equivalence of the measures in the different versions (English, French and Polish), back-translation will be performed to check and improve if necessary the final version of each questionnaire (Brislin, 1980). We will also collect public information about these firms through their internet sites.

\section{Results and discussion}

\section{General Results}

First of all, some correlations have been calculated between the general variables of the model. They are presented in Figure 2.

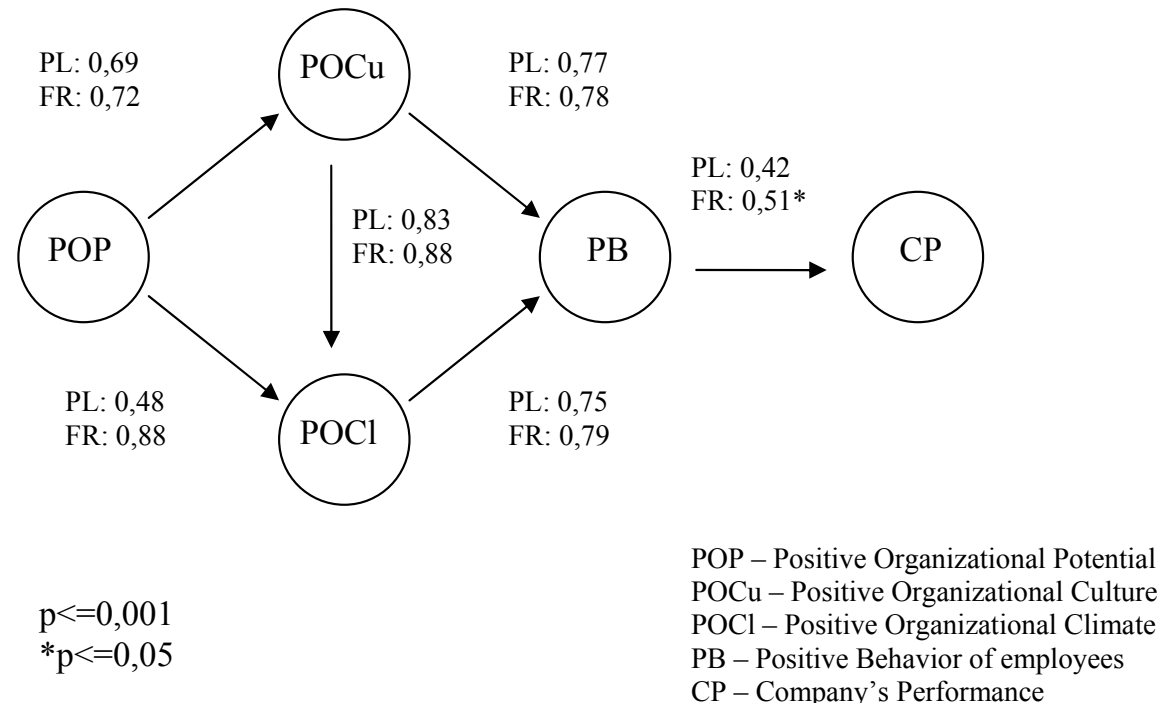

Figure 2 shows the assumptions of the model that have been approved by the results obtained within the research. Strong positive correlations were identified among all the variables in both samples. It means that, indeed, together with the increase of 'positiveness' of an organization's potential organizational culture and climate obtain more positive elements, which in turn seems to stimulate positive behaviour of employees and company's performance. Although correlations present only strength and direction of relationships, causality assumed in the model is very likely.

Part I of the questionnaire presented 35 statements describing development supporting employee behaviours. Managers were asked to indicate to what extent these statements characterize behaviours of employees in their company, on a scale 
POSITIVE ORGANIZATIONAL

Dominique Peyrat-Guillard Aldona Glińska-Neweś

Table 2.

$\mathrm{OCB}$ and $\mathrm{OC}$

in the French and

Polish samples ranging from 'I totally disagree' (0\%) to 'I agree entirely' (100\%). Among these behaviours, OCB has been measured in this first step by the following items:

- for the 'Helping' dimension:

Item number 23: 'Employees ask questions and ask their colleagues for help when they do not know something or cannot do something'

Item number 25: 'Employees provide support and information to their colleagues when they need it'

-for the 'General compliance' dimension:

Item number 15: 'Employees do not generate unnecessary costs'

As concerns Organizational Commitment, it has been measured in particular by these two items:

Item number 34: 'Employees talk proudly of their company'

Item number 35: 'Employees do not look for another job'

Table 2 presents the differences in the responses of the Polish and French samples for these items.

\begin{tabular}{lccccc}
\hline \multicolumn{1}{c}{$\begin{array}{c}\text { Concepts } \\
\text { measured }\end{array}$} & \multicolumn{2}{c}{$\begin{array}{c}\text { OCB: 'Helping' } \\
\text { dimension }\end{array}$} & $\begin{array}{c}\text { OCB: 'General } \\
\text { compliance' } \\
\text { dimension }\end{array}$ & \multicolumn{2}{c}{ OC } \\
\hline Items & Item no. 23 & Item no. 25 & Item no. 15 & Item no. 34 & Item no. 35 \\
\hline $\begin{array}{l}\text { Average \% in the } \\
\begin{array}{l}\text { French sample } \\
(\mathrm{N}=23)\end{array}\end{array}$ & $68.26 \%$ & $60.87 \%$ & $41.74 \%$ & $69.13 \%$ & $57.83 \%$ \\
\hline $\begin{array}{l}\text { Average \% in the } \\
\begin{array}{l}\text { Polish sample } \\
(\mathrm{N}=104)\end{array}\end{array}$ & $70.48 \%$ & $68.46 \%$ & $53.46 \%$ & $72.12 \%$ & $70.29 \%$ \\
\hline
\end{tabular}

It appears that in Table 2 the averages for the French sample are systematically lower than the ones for the Polish sample. We must be very careful in interpreting these first results that are based only on the averages of perceived measures but they can play the role of 'indicators' for our next step. The most important differences appear for the 'general compliance' dimension of OCB and for the willingness to continue membership, even if it is not possible here to determine if it is linked to the fact that people want, need or feel they ought to maintain this membership ${ }^{2}$. Indeed, items number 15 and number 35 are among the 6 items presenting the greatest differences between the two samples (more than $10 \%$ of the average calculated). Among the other items presenting such a difference, it is interesting to note that behaviours seem to be more 'suspicious' in the French sample: the average percentage for the items number 18 ('Employees talk openly with one

${ }^{2}$ The nature of organizational commitment cannot be precised for the item number 35 . Item number 34 refers to the affective nature of commitment 
another'- France 43.48\% and Poland 58.85\%), number 19 ('Employees reveal their dreams and passions' - France 40\% and Poland 53.37\%) and number 33 ('When competing with others, employees follow the rules of fair play' - France 43.91\% and Poland 56.63\%) are also systematically lower in the French sample. The analysis of the responses of the Part II of the questionnaire on positive culture is coherent with this, showing that among the elements in the system of cultural values, 'Openness' (France: 53.91\% / Poland: 64.80\%), 'Honesty' (France: 58.70\% / Poland: 76.35\%), 'Respecting truth' (France: 59.57\% / Poland: 72.31\%) appear among the most important differences (more than 10\% of the average calculated) with scores lower for the French sample.

As regards part III of the questionnaire (positive climate), we will examine in more detail the results concerning team commitment that are connected closer to the focus we have chosen here, compared to the other elements of this part of the questionnaire (clarity, rewarding, standards, flexibility and responsibility). Table 3 shows that the differences are important.

\begin{tabular}{lcc}
\hline \multicolumn{1}{c}{$\begin{array}{l}\text { Items measuring } \\
\text { Team commitment }\end{array}$} & $\begin{array}{c}\text { Average } \% \text { in the } \\
\text { French sample } \\
(\mathrm{N}=23)\end{array}$ & $\begin{array}{c}\text { Average \% in the } \\
\text { Polish sample } \\
(\mathrm{N}=104)\end{array}$ \\
\hline $\begin{array}{l}\text { 1. Conviction that the company is something to be } \\
\text { proud of }\end{array}$ & $65.22 \%$ & $73.17 \%$ \\
\hline 2. Positive attitude towards colleagues & $63.91 \%$ & $75.38 \%$ \\
\hline $\begin{array}{l}\text { 3. Conviction that you co-operate with people striving } \\
\text { for achievements }\end{array}$ & $61.30 \%$ & $72.69 \%$ \\
\hline 4. Feeling of team solidarity, feeling of team integrity & $59.13 \%$ & $72.12 \%$ \\
\hline $\begin{array}{l}\text { 5. Feeling of the possibility of obtaining support from } \\
\text { the company (in the case of personal problems) }\end{array}$ & $54.35 \%$ & $77.31 \%$ \\
\hline
\end{tabular}

More generally, except one mean percentage at the same level for the two samples (concerning the feeling of satisfactory earnings), all other mean percentages of this part of the questionnaire concerning positive organizational climate are lower in the French sample compared to the Polish one.

The analysis of the results concerning the positive potential of the organization (part IV of the questionnaire) also shows lower scores of the French sample, particularly interesting in the case of the items concerning strategy, HRM, power and innovations (examples are given in Table 4).

The more 'suspicious' behaviours described earlier concerning the French sample seem to be coherent with these characteristics of the French organizations.

Due to these lower scores for the French sample of the determinants of our model, it would be logical to obtain lower results concerning the consequences, in terms of Organizational Development. In fact, the answers concerning the
POSITIVE ORGANIZATIONAL

Dominique Peyrat-Guillard Aldona Glińska-Neweś

Table 3.

Characteristics of the positive climate: team commitment 
POSITIVE ORGANIZATIONAL

Dominique Peyrat-Guillard Aldona Glińska-Neweś

Table 4.

Characteristics of the positive potential of the organization

Table 5.

Characteristics of the selected French and Polish firms development of the company (part $\mathrm{V}$ of the questionnaire) show that the lowest mean average (among all the items of this part) concerns the item 'In the years 2006-2008 we had a considerable growth in employee's satisfaction', with only $47.50 \%$ for France, compared to $66.50 \%$ for Poland. Differences are also significant in two other items of this part of the questionnaire: 'In the years 2006-2008 we had a considerable growth in customers' satisfaction' (France: $57.50 \%$ / Poland: 70.29\%) and 'In the years 2006-2008 we had a considerable growth of the company's renown' (France: 61.43\% / Poland: 74.70\%).

\begin{tabular}{lcc}
\hline \multicolumn{1}{c}{$\begin{array}{l}\text { Items measuring } \\
\text { Positive potential }\end{array}$} & $\begin{array}{c}\text { Average \% in the } \\
\text { French sample } \\
(\mathrm{N}=23)\end{array}$ & $\begin{array}{c}\text { Average \% in the } \\
\text { Polish sample } \\
(\mathrm{N}=104)\end{array}$ \\
\hline $\begin{array}{l}\text { Strategy: } \\
\text { 'In the process of strategy formulation employees are } \\
\text { asked for their opinions and these opinions are conside- } \\
\text { red' }\end{array}$ & $40.43 \%$ & $60.58 \%$ \\
\hline $\begin{array}{l}\text { HRM: } \\
\text { In motivation systems - rewarding employees in the form } \\
\text { of stock options increasing the company's value - rules of } \\
\text { this type of rewarding are clear and known to everybody' }\end{array}$ & $21.74 \%$ & $50.10 \%$ \\
\hline $\begin{array}{l}\text { Power: } \\
\text { Manager functions as a coach, promoter and not as a } \\
\text { supervisor' }\end{array}$ & $41.74 \%$ & $67.40 \%$ \\
$\begin{array}{l}\text { NO nepotism (in employing, promoting, rewarding, ...) } \\
\text { Innovations: }\end{array}$ & $36.09 \%$ & $71.83 \%$ \\
$\begin{array}{l}\text { Respecting authorship of innovative ideas (superiors do } \\
\text { not add their names to ideas created by subordinates' }\end{array}$ & $45.65 \%$ & $74.04 \%$ \\
\hline
\end{tabular}

\section{A focus on two French and two Polish firms selected for next step}

In order to make finer grained comparisons, we have selected two firms from the general sample. Their characteristics are presented in Table 5.

\begin{tabular}{lcccc}
\hline \multicolumn{1}{c}{ Characteristics } & \multicolumn{2}{c}{ First 'pair' of firms } & \multicolumn{2}{c}{ Second 'pair' of firms } \\
\hline Country & France $(\mathrm{F})$ & Poland $(\mathrm{P})$ & France $(\mathrm{F})$ & Poland $(\mathrm{P})$ \\
\hline Sector & $\begin{array}{l}\text { Industry, } \\
\text { high-tech }\end{array}$ & $\begin{array}{c}\text { Industry, } \\
\text { high-tech }\end{array}$ & Energy & Energy \\
\hline Number of Employees & 220 & 250 & 1000 & 1843 \\
\hline
\end{tabular}

The responses of these four firms on main items of the model are presented on figures 2 to 5 . On these figures, the elements chosen concerning 'POP, culture and climate' are the one of table 4 concerning strategy, HRM and power; the 
3 elements of cultural values mentioned above and the 5 elements of climate presented in table 3. As concerns the elements chosen for 'OC, OCB and OD', they correspond to the ones of Table 2 for OC and OCB and the three items concerning OD mentioned above.
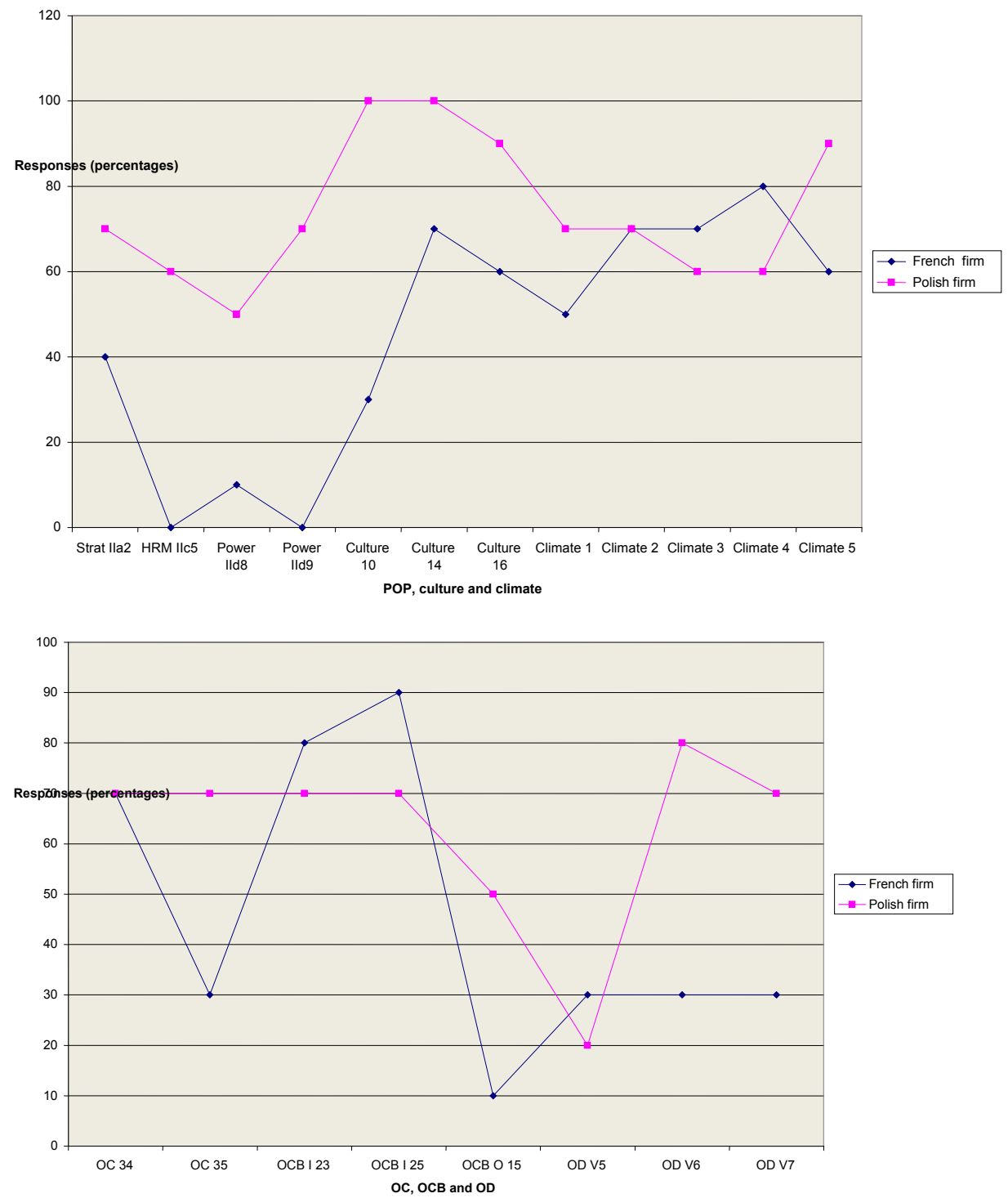

In Figure 3, we can observe that the Polish firm presents a better 'profile' than the French firm on POP, culture and climate, except for two items referring to climate.
POSITIVE ORGANIZATIONAL

Dominique Peyrat-Guillard Aldona Glińska-Neweś

Figure 3. Characteristics of POP, culture and climate in the first 'pair' of firms

Figure 4. Characteristics of OC, OCB and OD in the first pair of firms 
POSITIVE

ORGANIZATIONAL

Dominique Peyrat-Guillard Aldona Glińska-Neweś

\section{Figure 5.}

Characteristics of POP, culture and climate in the second 'pair' of firms

\section{Figure 6.}

Characteristics of $\mathrm{OC}, \mathrm{OCB}$ and OD in the second pair of firms
This is coherent with the behaviours and consequences observed in Figure 4: the good climate in the French firm goes along with rather good results in terms of OC, OCB and employee satisfaction (OD V5). However, the Polish firm obtains better results for two other elements of OD (customers' satisfaction and company's renown). The same pattern of behaviours, as in the whole samples, appear for the 'general compliance' dimension of OCB (item OCB O15) and for willingness to continue membership in the organization (item OC 35), with percentages lower in the French firm.
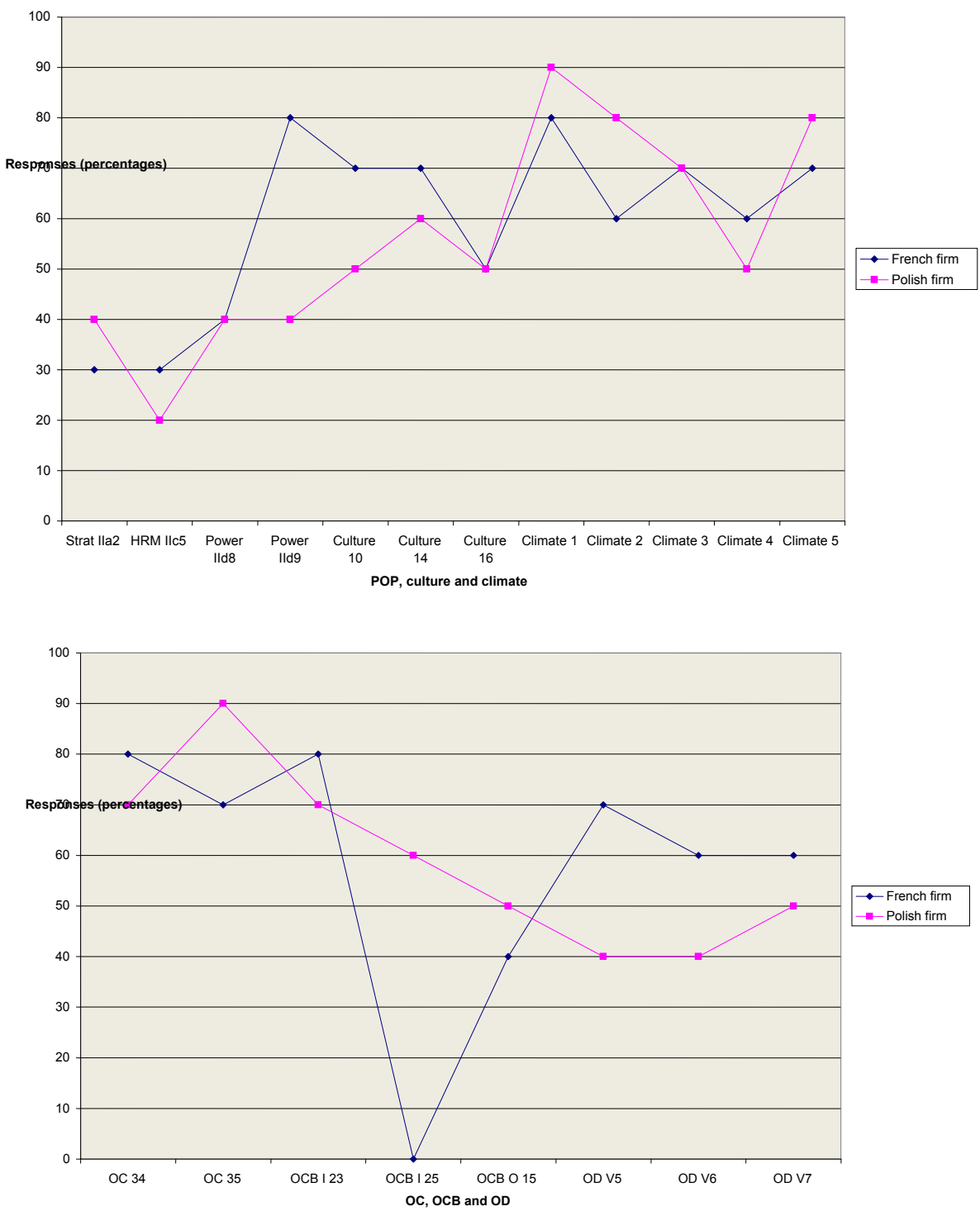
The characteristics concerning the second 'pair' of firms (Figure 5) show that the French firm presents better scores than the Polish firm for 5 items, the same score for 3 items and lower scores for only 4 items. These characteristics are in line with the ones of Figure 6, with a total of 5 better scores and 3 lower scores (among which the items OCB O15 and OC 35 corresponding to the general pattern of behaviours of the whole samples). Among these scores, results in the terms of OD are better for the French firm.

These first results support our model and thus the importance of POP, culture and climate on behaviours and OD. They also point out cultural differences between the French and Polish firms: one dimension of OC, the willingness to continue membership in the organization and the general compliance dimension of OCB are lower in the French sample. These results present limitations in particular due to the cross-sectional nature of our samples. However, it seems interesting to launch the next step, a more thorough one, in order to understand better the relations holding between the variables of our model and the cultural differences.

\section{References}

Allen, N.J. \& Meyer, J.P. (1990). "The measurement and antecedents of affective, continuance and normative commitment to the organization", Journal of Occupational Psychology, 63, pp. 1-18.

Borman, W.C. \& Motowidlo, S.J. (1993). "Expanding the criterion domain to include elements of contextual performance" in: N. Schmitt \& W.C. Borman (Eds.), Personality selection, San Francisco: Jossey-Bass, pp. 71-98.

Brislin, R.W. (1980). "Translation and content analysis of oral and written material", in: H.C. Triandis \& J.W. Berry (Eds), Handbook of cross-cultural psychology: vol. 2, Methodology, Boston: Allyn \& Bacon, pp. 349-444.

Cameron, K.S., Dutton, J.E. \& Quinn, R.E. (Eds.) (2003). Positive Organizational Scholarship: Foundations of a New Discipline, San Francisco: Berrett-Koehler.

Caza A., Barker B.A., Cameron K., (2007) Virtues and Ethics: Values in Organizations, http://www.bus.umich.edu/Positive/Center-for-POS/Publications-Working-Papers.htm.

Cialdini R.B. (2007), Influence. The Psychology of Persuasion, Collins Business.

Drucker P. (2005), Manging Yourself, Harvard Business Review, January, pp. 100-109.

Dutton J.E., Heaphy E.D. (2003), "The Power of High-Quality Connections", in: Positive

Organizational Scholarship: Foundations of a New Discipline, ed. K. S. Cameron, J. E. Dutton, R. E. Quinn, Berrett-Koehler Publishers, San Francisco

Fineman, S. (2006) "On being positive: concerns and counterpoints", Academy of Management Review, 31, 2, pp. 270-291.

Fredrickson B.L. (2003), "Positive Emotions and Upward Spirals in Organizations", in: Positive Organizational Scholarship: Foundations of a New Discipline, ed. K. S. Cameron, J. E. Dutton, R. E. Quinn, Berrett-Koehler Publishers, San Francisco. 
POSITIVE

ORGANIZATIONAL

Dominique Peyrat-Guillard Aldona Glińska-Neweś
Fryer B. (2004), Accentuate the Positive, Harvard Business Review: Breakthrough Ideas for 2004, February, pp. 13-14.

Haffer R. (2010), „Relacje pomiędzy komponentami modelu wewnatrzorganizacyjnych oddziaływań Pozytywnego Potencjału Organizacji” in: M.J.Stankiewicz (ed.) Pozytywny Potencjat Organizacji. Wstęp do użytecznej teorii zarządzania, Dom Organizatora TNOiK, Toruń, pp. 159-214.

Meyer, J.P. \& Allen, N.J. (1997). Commitment in the workplace - Theory, research and application, Sage Publications.

Organ, D.W. (1988). Organizational citizenship behavior: The good soldier syndrome. Lexington, MA: Lexington.

Organ, D.W. (1997). Organizational Citizenship Behavior: It's Construct Clean-Up Time, Human Performance, 10, 2, pp. 85-97.

Podsakoff, P.M., Ahearne, M. \& MacKenzie, S.B. (1997). Organizational Citizenship Behavior and the Quantity and Quality of Work Group Performance, Journal of Applied Psychology, 82, 2, pp. 262-270.

Podsakoff, P.M., MacKenzie, S.B., Paine, J.B. \& Bachrach, D.G. (2000). Organizational Citizenship Behaviors: A Critical Review of the Theoretical and Empirical Literature and Suggestions for Future Research, Journal of Management, 26, 3, pp. 513-563.

Ragins B. R., Dutton J. E. (2007), Positive Relationships At Work: An Introduction and Invitation, [in:] Exploring Positive Relationships At Work: Building a Theoretical and Research Foundation, J. E. Dutton, B. R. Ragins (ed.), , Laurence Erlbaum Associates, Mahwah.

Roberts L.M., Spreitzer G., Dutton J., Quinn R., Heaphy E., Barker B. (2005), "How to Play to Your Strengths", Harvard Business Review, no. 1, January.

Smith, C.A., Organ, D.W. \& Near, J.P. (1983). "Organizational Citizenship Behavior: Its Nature and Antecedents", Journal of Applied Psychology, 68, 4, pp. 653-663.

Williams, L.J. \& Anderson, S.E. (1991). "Job satisfaction and organizational commitment as predictors of organizational citizenship and in-role behaviour", Journal of Management, 17, pp. 601-617. 


\section{Appendix 1: Measures of Organizational Commitment (Source: Meyer \& Allen, 1997, pp. 118-119)}

\footnotetext{
1. I would be very happy to spend the rest of my career in this organization.

2. I enjoy discussing my organization with people outside it.

3. I really feel as if this organization's problems are my own.

Affective
Commitment
Scale Items

4. I think I could easily become as attached to another organization as I am to this one. (R)

5. I do not feel like 'part of the family' at my organization. (R)

6. I do not feel 'emotionally attached' to this organization. (R)

7. This organization has a great deal of personal meaning for me.

8. I do not feel a strong sense of belonging to my organization. (R)

1. I think that people these days move from company to company too often.

2. I do not believe that a person must always be loyal to his or her organization. (R)

3. Jumping from organization to organization does not seem at all unethical to me. (R)

Normative

Commitment

Scale Items

4. One of the major reasons I continue to work for this organization is that I believe loyalty is important and therefore feel a sense of moral obligation to remain.

5. If I got another offer for a better job elsewhere, I would not feel it was right to leave my organization.

6. I was taught to believe in the value of remaining loyal to one organization.

7. Things were better in the days when people stayed with one organization for most of their careers.

8. I do not think that wanting to be a 'company man' or 'company woman' is sensible anymore. (R)

1. I am not afraid of what might happen if I quit my job without having another one lined up. (R)

2. It would be very hard for me to leave my organization right now, even if I wanted to.

3. Too much of my life would be disrupted if I decided I wanted to leave my organization right now.

4. It wouldn't be too costly for me to leave my organization in the near future. (R)

Continuance

Commitment

Scale Items

5. Right now, staying with my organization is a matter of necessity as much as desire.

6. I believe that I have too few options to consider leaving this organization.

7. One of the few negative consequences of leaving this organization would be the scarcity of available alternatives.

8. One of the major reasons I continue to work for this organization is that leaving would require considerable personal sacrifice; another organization may not match the overall benefits I have here.

9. If I had not already put so much of myself into this organization, I might consider working elsewhere.

(R) indicates a reverse-keyed item (scoring is reversed). The respondents are asked to indicate if they agree or not with each statement on a 7-point scale. (1: strongly disagree; 2: disagree; 3 : rather disagree;

4: neither disagree nor agree; 5 : rather agree; 6: agree; 7: strongly agree).
}

POSITIVE ORGANIZATIONAL

Dominique Peyrat-Guillard Aldona Glińska-Neweś 
POSITIVE

ORGANIZATIONAL

Dominique Peyrat-Guillard Aldona Glińska-Neweś

\section{Appendix 2: Measure of Organizational Citizenship Behaviour (Source: Smith, Organ \& Near, 1983, 657)}

\author{
OCB (Altruism \\ and Generalized \\ 1. Helps others who have been absent. \\ 2. Punctuality. \\ Compliance) \\ 3. Volunteers for things that are not required. \\ 4. Takes undeserved breaks. (R) \\ 5. Orients new people even though it is not required. \\ 6. Attendance at work is above the norm. \\ 7. Helps others who have heavy work loads. \\ 8. Coasts towards the end of the day. (R) \\ 9. Gives advance notice if unable to come to work.
}

10. Great deal of time spent with personal phone conversations. (R)

11. Does not take unnecessary time off work.

12. Assists supervisor with his or her work.

13. Makes innovative suggestions to improve department.

14. Does not take extra breaks.

15. Attend functions not required but that help company image.

16. Does not spend time in idle conversation.

(R) indicates a reverse-keyed item (scoring is reversed). The respondents are asked to indicate if these behaviours are characteristic or not of their own behaviours on a 7-point scale. (1: strongly disagree;

2: disagree; 3: rather disagree; 4: neither disagree nor agree; 5: rather agree; 6: agree; 7: strongly agree). 